Cynthia L. H enderson MD FRCPC,* Josie Schmid MD,*

$\mathrm{H}$ imat Vaghadia M B BS MHSC FCA FRCPC, ${ }^{*} \dagger$

Carolyn Fowler MBCH B FANZCA,*

G.W.E. M itchell MB CHB FRCOG FRCS (ed) FRCSC‡

\title{
Selective spinal anesthesia for outpatient laparoscopy. III: Sufentanil vs lidocaine-sufentanil
}

Purpose: The efficacy of low dose intrathecal lidocaine-sufentanil was compared with intrathecal sufentanil for short duration outpatient gynecological laparoscopy.

M ethods: Thirteen ASA I and II patients undergoing gynecological laparoscopy were studied in a randomized double-blind trial. Patients received either intrathecal $10 \mathrm{mg}$ lidocaine plus $10 \mu \mathrm{g}$ sufentanil (G roup LS) or intrathecal $20 \mu \mathrm{g}$ sufentanil (Group S), each diluted to $3 \mathrm{~mL}$ with sterile water through a $27 \mathrm{~g} \mathrm{~W}$ hitacre needle in the sitting position. Sensory and motor recovery were assessed with pinprick and a modified Bromage scale.

Results: $O$ ne of seven G roup LS patients and two of five Group S patients required conversion to general anesthesia for failed skin test with forceps. Two of the remaining three Group $S$ patients felt sharpness with skin incision. The study was terminated early because of inadequate anesthesia in Group $S$. The small sample size $(n=9)$ made statistical analysis uninformative.

Conclusion: Intrathecal $20 \mu \mathrm{g}$ sufentanil is unsuitable as a sole agent for gynecological laparoscopy.

O bjectif : Comparer l'efficacité de l'injection intrathécale d'une faible dose de lidocaïne-sufentanil au sufentanil seul dans le contexte d'une laparoscopie gynécologique ambulatoire de courte durée.

M éthode : L'essai randomisé et à do uble insu a porté sur 13 patientes, ASA I et II, qui devaient subir une laparoscopie gynécologique. $0 \mathrm{n}$ a procédé à l'injection intrathécale, soit $10 \mathrm{mg}$ de lidocaine plus $10 \mu \mathrm{g}$ de sufentanil (groupe LS), soit $20 \mu \mathrm{g}$ de sufentanil (groupe S), complétés dans chaque cas au volume de $3 \mathrm{~mL}$ avec de l'eau stérile et administrés, en position assise, à l'aide d'une aiguille W hitacre de calibre 27 . La récupération sensitive et motrice a été évaluée par la réaction à la piqûre et par une échelle de Bromage modifiée.

Résultats : Une des sept patientes du groupe LS et deux des cinq patientes du groupe $S$ ont eu beso in d'anesthésie générale à la suite de l'échec du test cutané avec l'utilisation des forceps. Deux des tro is patientes restantes du groupe $S$ ont ressenti un inconfort à l'incision cutanée. L'anesthésie étant insuffisante dans le groupe $S$, on a dû arrêter l'étude plus tôt. Le petit nombre de sujets $(n=9)$ a rendu l'analyse statistique inutile.

Conclusion : L'administration intrathécale de $20 \mu \mathrm{g}$ de sufentanil seul est inadéquate pour la laparoscopie gynécologique.

From the D epartments of Anesthesia,* $\mathrm{H}$ ealth Care and E pidemiology, $†$ and Gynaecology, $\neq$ Vancouver General H ospital, U niversity of British Columbia, Vancouver BC, Canada.

A ddress correspondence to: D r. Cynthia H enderson, D epartment of Anesthesia, Vancouver General H ospital, 855 West 12 th Avenue, Vancouver, BC, Canada V5Z 1M 9. E-mail: chenders@vanhosp.bc.ca

A ccepted for publication October 29, 2000. 
A LTHOUGH short duration outpatient gynecological laparoscopy is usually performed on patients under general anesthesia, there are recent publications describing effective anesthesia for laparoscopy using small-dose hypobaric lidocaine-fentanyl spinal anesthesia., ${ }^{1,2}$ While this technique results in less motor block, faster sensory recovery and earlier discharge compared with conventional dose spinal anesthesia, ${ }_{1}^{1}$ doses of lidocaine as low as $10 \mathrm{mg}$ still produce mild motor weakness of the lower extremities in some patients. In addition, complete return of sensation to pinprick remains the ratelimiting step to early discharge. ${ }^{1-4}$ Intrathecal sufentanil (ITS) as a sole agent has been used successfully for analgesia during labour and delivery, ${ }^{5}$ and extracorporeal shock wave lithotripsy, ${ }^{6}$ while preserving motor function of the lower extremities.

We hypothesized that ITS alone would provide adequate surgical conditions for short duration outpatient gynecological laparoscopy, while achieving the goal of early discharge with fully intact sensory and motor function. In the present study, intrathecal sufentanil was compared with small-dose hypobaric lidocaine-sufentanil spinal anesthesia for laparoscopy with respect to operating conditions, recovery of function, and side effects.

M ethods

The study was conducted as a single-centre, randomized, prospective double-blind trial. Institutional and university ethics approvals were obtained along with written informed consent from each patient recruited. Exclusion criteria were neurological or neuromuscular disease, infection at the intended site of needle insertion for spinal anesthesia, coagulopathy, and allergy to lidocaine or sufentanil.

Thirteen ASA I and II women scheduled to undergo outpatient gynecological laparoscopic procedures of less than 60 min duration were enrolled in the study and randomized to two groups. Group LS received a hypobaric solution of $10 \mathrm{mg}$ lidocaine $1 \%$ with $10 \mu \mathrm{g}$ sufentanil diluted with sterile water to a total volume of $3 \mathrm{ml}$. Group $\mathrm{S}$ received a hypobaric solution of $20 \mu \mathrm{g}$ sufentanil, mixed in sterile water to a final volume of $3 \mathrm{~mL}$. Solutions were prepared aseptically by an anesthesiologist not performing the anesthetic and both solutions appeared identical.

An intravenous (iv) infusion of sodium chloride $0.9 \%$ was established preoperatively. In the operating room, patients were monitored with an ECG, pulse oximeter, and automatic blood pressure cuff. Spinal anesthesia was administered in the sitting position with a midline approach at the $L_{3-4}$ level using a $27 \mathrm{~g}$ Whitacre spinal needle through an introducer. The solution was injected, after aspiration of cerebrospinal fluid, as rapidly as possible in a single shot with the bevel cephalad. After sitting for one minute, the patient was placed in 20 to $30^{\circ}$ reverse Trendelenberg while lithotomy positioning and skin preparation occurred.

The extent of motor blockade and sensory loss to pinprick were measured at three and five minutes post spinal injection, prior to the surgical start. Testing the skin with toothed forceps prior to surgery was instituted after the third subject (Group S). She was the first patient to note sharpness during trocar insertion, in spite of blunted sensation to pinprick testing at three and five minutes. Patients were placed in Trendelenberg during carbon dioxide $\left(\mathrm{CO}_{2}\right)$ insufflation into the peritoneum to minimize diaphragmatic irritation from $\mathrm{CO}_{2}$ and consequent shoulder tip pain.

Intrao perative patient comfort was continually evaluated by verbal communication, and discomfort was graded by the patient as mild, moderate, or severe. In the presence of an obviously inadequate block (defined as sharp sensation when testing the abdomen with toothed forceps) a GA was induced. Anxiety and abdominal or shoulder discomfort were treated with increments of $1 \mathrm{mg}$ midazolam and $250 \mu \mathrm{g}$ alfentanil iv, respectively. Surgical conditions were graded by the surgeon as poor, fair, good, or excellent.

Assessment in the recovery room consisted of sensory and motor block measurements and evaluation of pruritus on arrival and every $30 \mathrm{~min}$. Sensation to pinprick was assessed with a $20 \mathrm{~g}$ needle until the $\mathrm{S}_{1}$ dermatome at the lateral aspect of the foot normalized. $M$ otor block was assessed with a modified Bromage scale $^{7}$ until the patient was able to perform a deep knee bend independently. Pruritus was evaluated using a sliding Visual Analogue Scale anchored at 0 (no pruritus) and 10 (maximum pruritus), and evaluations were discontinued when pruritus became absent or the patient was discharged. Patients reporting pruritus were offered treatment with $40 \mu \mathrm{g}$ naloxone iv and reassessed after 15 min when the dose was repeated if necessary. $\mathrm{N}$ ausea and abdominal pain were graded according to the most severe manifestation over the duration of recovery, using a modified Prince $\mathrm{H}$ enry Pain Scale. ${ }^{8} \mathrm{~A}$ measurement of satisfaction was obtained just before discharge by asking the patient: "If you had to have the surgery again would you choose the same spinal anesthetic?"

\section{Results}

Thirteen women age 32-72 yr were enrolled. O ne was excluded after she developed abrupt onset of paresthesia coincident with the beginning of subarachnoid 
TABLE I Intraoperative characteristics of small- dose spinal lidocaine-sufentanil (Group LS) vs sufentanil (Group S)

\begin{tabular}{|c|c|c|c|c|c|c|c|c|c|c|}
\hline & \multirow{2}{*}{\multicolumn{2}{|c|}{$\begin{array}{l}\text { Sensory } \\
\text { level at }\end{array}$}} & \multirow{2}{*}{$\begin{array}{l}\text { M otor } \\
\text { block† }\end{array}$} & \multirow{2}{*}{$\begin{array}{l}\text { Surgical } \\
\text { conditionsł }\end{array}$} & \multirow{2}{*}{\multicolumn{2}{|c|}{\begin{tabular}{ll}
\multicolumn{3}{c}{ Supplements } \\
midazolam & alfentanil \\
$(\mathrm{mg})$ & $(\mu \mathrm{g})$
\end{tabular}}} & \multirow[b]{2}{*}{$\begin{array}{l}\text { Shoulder } \\
\text { ache }\end{array}$} & \multicolumn{2}{|c|}{ Complications* } & \multirow[b]{2}{*}{$\begin{array}{l}\text { A bdominal } \\
\text { discomfort }\end{array}$} \\
\hline & & $5^{\prime}$ & & & & & & N ausea & $\begin{array}{l}\text { I nadequate } \\
\text { block }\end{array}$ & \\
\hline \multicolumn{11}{|c|}{ Group LS } \\
\hline 1 & $\mathrm{~T}_{10}$ & $\mathrm{~T}_{5}$ & 4 & excellent & 0 & 0 & mod & 0 & 0 & mild \\
\hline 2 & $\mathrm{~T}_{11}^{10}$ & $\mathrm{~T}_{6}$ & 4 & good & 0 & 0 & mild & 0 & 0 & 0 \\
\hline 3 & $\mathrm{~T}_{6}^{11}$ & $\mathrm{~T}_{4}^{6}$ & 4 & fair & 1 & 250 & 0 & 0 & 0 & mild \\
\hline 4 & $\mathrm{~T}_{10}$ & $\mathrm{~T}_{9}$ & 4 & good & 0 & 0 & 0 & 0 & 0 & 0 \\
\hline 5 & $\mathrm{~T}_{9}$ & $\mathrm{~T}_{7}$ & 4 & good & 0 & 250 & 0 & 0 & 0 & $\bmod$ \\
\hline 6 & $\mathrm{~T}_{6}^{9}$ & $\mathrm{~T}_{6}^{\prime}$ & 4 & good & 0 & 500 & $\bmod$ & 0 & 0 & 0 \\
\hline 7 & $\mathrm{~T}_{4}^{\circ}$ & $\mathrm{T}_{5}^{0}$ & 4 & GA & G A & GA & GA & GA & GA & G A \\
\hline Mean & $\mathrm{T}_{8}$ & $T_{6}$ & 4 & & 0.17 & 166.7 & & & & \\
\hline \multicolumn{11}{|c|}{ Group S } \\
\hline Patient & & & & & & & & & & \\
\hline 1 & $T_{6}$ & $\mathrm{~T}_{4}$ & 4 & good & 1 & 500 & 0 & 0 & mild & mild \\
\hline 2 & $\mathrm{~T}_{9}^{0}$ & $\mathrm{~T}_{8}^{4}$ & 4 & $\mathrm{GA}$ & G A & $\mathrm{GA}$ & GA & GA & GA & G A \\
\hline 3 & $\mathrm{~T}_{6}$ & $\mathrm{~T}_{4}^{\circ}$ & 4 & good & 0 & 0 & 0 & 0 & 0 & 0 \\
\hline 4 & $T_{6}^{0}$ & $\mathrm{~T}_{4}^{4}$ & 4 & $\mathrm{GA}$ & G A & GA & GA & GA & $\mathrm{GA}$ & G A \\
\hline 5 & $\mathrm{~T}_{5}^{0}$ & $\mathrm{~T}_{4}^{4}$ & 4 & good & 2 & 750 & $\bmod$ & 0 & mild & mild \\
\hline Mean & $T_{6.4}$ & $\mathrm{~T}_{4.8}^{4}$ & 4 & & 1 & 416.7 & & & & \\
\hline
\end{tabular}

* Graded by the surgeon

† M odified Bromage scale: $1=$ unable to move feet or knees, $2=$ moves foot/ feet, $3=$ moves knee/ knees, $4=$ straight leg raise

$\ddagger$ Graded on a scale: $0=$ not present, $1=$ mild, $2=$ mod, $3=$ severe

$\mathrm{GA}=$ general anesthestic conversion; data ineligible for consideration

TABLE II Recovery characteristics of small-dose spinal lidocaine-sufentanil (Group LS) vs sufentanil (Group S)

\begin{tabular}{|c|c|c|c|c|c|}
\hline & $\begin{array}{l}\text { Time to } \\
\mathrm{S}_{1} \text { Sensation* } \\
\text { (min) }\end{array}$ & $\begin{array}{l}\text { Timeto } \\
\text { Motor R ecovery* } \\
\text { (min) }\end{array}$ & $\begin{array}{l}\text { Timeto } \\
\text { ambulation } \ddagger \\
\text { (min) }\end{array}$ & $\begin{array}{l}\text { Pruritis } \\
\text { (VAS/10) }\end{array}$ & $\mathrm{N}$ ausea $\dagger$ \\
\hline \multicolumn{6}{|c|}{ Group LS } \\
\hline \multicolumn{6}{|c|}{ Patient } \\
\hline 1 & 120 & 0 & 37 & 4.25 & 0 \\
\hline 2 & 90 & 0 & 25 & 0.25 & severe \\
\hline 3 & 120 & 60 & 93 & 8.00 & 0 \\
\hline 4 & 30 & 0 & 21 & 3.50 & 0 \\
\hline 5 & 30 & 0 & 35 & 5.00 & 0 \\
\hline 6 & 60 & 0 & 34 & 3.25 & mild \\
\hline 7 & GA & $\mathrm{GA}$ & $\mathrm{GA}$ & GA & GA \\
\hline Mean & 75 & & 40.8 & 4.04 & \\
\hline \multicolumn{6}{|c|}{ Group S } \\
\hline \multicolumn{6}{|c|}{ Patient } \\
\hline 1 & 90 & 30 & 61 & 2.00 & severe \\
\hline 2 & GA & $\mathrm{GA}$ & GA & GA & $\mathrm{GA}$ \\
\hline 3 & 60 & 0 & 30 & 4.50 & 0 \\
\hline 4 & $\mathrm{GA}$ & $\mathrm{GA}$ & $\mathrm{GA}$ & GA & $\mathrm{GA}$ \\
\hline 5 & 30 & 0 & 29 & 5.00 & severe \\
\hline M ean & 60 & & 40 & 3.83 & \\
\hline
\end{tabular}

* From time of arrival in recovery room to time of sensory or motor recovery (return of S1 sensation to pinprick $\&$ ability to deep knee bend, respectively)

$\ddagger$ From time of spinal injection to time of first successful independent ambulation

† $M$ aximal grade of nausea experienced: absent, mild, moderate-no vomiting, severe-vomiting

$\mathrm{GA}=$ general anesthetic conversion; data ineligible for consideration 
injection, which was immediately discontinued. General anesthesia (GA) was induced and the patient recovered uneventfully, with no neurological deficit.

The study was terminated early on ethical grounds because a large number of unacceptable blocks occurred compared to our usual experience with low dose local anesthetic and opioid mixtures. Two of five (40\%) Group S patients had inadequate sensory block of the abdomen, as determined by the toothed forceps test, and one of seven (14\%) Group LS patients had sharp perineal sensation without abdominal testing, and were converted to GA. A further two of the remaining three (67\%) Group S patients, who passed the forceps test, felt mild transient sharpness during skin incision. Patients who received GA were excluded from the intraoperative ( $T$ able I) and recovery data (Table II).

Abdominal cramping and shoulder tip pain associated with $\mathrm{CO}_{2}$ insufflation were common (three of six in Group LS and two of three in Group S). O nly one of three Group $S$ patients was satisfactorily comfortable with one dose or less of alfentanil, whereas five of six Group LS patients were comfortable with this dose. $\mathrm{H}$ igher doses of alfentanil may be related to increased postoperative nausea and vomiting (PON V) but this was difficult to interpret from the small amount of data. O ne of three Group LS patients compared with two of three Group $S$ patients experienced some degree of PONV. Frequency of pruritus was similar between groups, and only one patient required treatment. Recovery of sensation to pinprick ( $75 \mathrm{~min}$ vs $60 \mathrm{~min}$ ), and time to ambulation ( 40.8 vs $40 \mathrm{~min}$ ) were similar in Group LS vs Group S. All the patients who did not require conversion to a GA were satisfied with the technique of spinal anesthetic and would choose it again.

The small sample size ( $G$ roup LS $n=6$, Group $S$ $n=3$ ) made statistical analysis uninformative.

\section{Discussion}

The study attempted to compare two hypobaric spinal anesthetic solutions for short duration outpatient gynecological laparoscopic procedures to determine if more rapid recovery of motor function and sensation to pinprick (the rate-limiting step to discharge ${ }^{1}$ ) could be achieved without compromising surgical conditions. During the study, it became evident that the usual depth of anesthesia provided by small dose spinal anesthesia was not being met in all subjects. O nly one of five (20\%) Group S patients had adequate anesthesia during trocar insertion at the beginning of laparoscopy. This success rate was felt to be sufficiently low to warrant early closure of the study on ethical grounds, even though the goal of 20 patients (10 per group) was not achieved and the small sample size did not allow for meaningful statistical analysis.

Interestingly, a "level" of dullness to pinprick was always established in Group S patients, reflecting the profound segmental antinociception of intrathecal opioids. ${ }^{9}$ Sufentanil has no local anesthetic effect on nerve conduction in isolated dorsal root axons when it is administered in clinically relevant concentrations. ${ }^{10}$ In labouring women receiving ITS, the lack of sympathectomy, as measured by differences between calf and toe temperatures, and normal motor strength also support the fact that sufentanil does not act significantly as a local anesthetic. ${ }^{11}$ The decrease in blood pressure after ITS for labour analgesia is not caused by sympathectomy, but rather due to pain relief. ${ }^{11}$ In male volunteers, ITS does not affect blood pressure, yet other effects of sufentanil including pruritus and sensory changes to pinprick and cold are similar to those in women during labour. ${ }^{12}$

Achievement of a differential level of sensation to pinprick in Group S patients did not reliably translate into adequate anesthesia for laparoscopy. Local anesthetics and opioids are frequently used together during spinal and epidural anesthesia for their dose-sparing effects to minimize toxicity and side effects. A study of intrathecal sufentanil and epidural bupivacaine alone and in combination in women during labour showed that markedly reduced doses of local anesthetics and opioids can be used in combination to provide adequate analgesia compared to either drug alone. ${ }^{13}$ Isobolographic evaluation concluded that ITS and epidural bupivacaine had a potentially synergistic interaction, although a purely additive interaction could not be excluded due to the study design. ${ }^{13}$ It is likely that the equivalent dose of intrathecal $10 \mathrm{mg}$ lidocaine with $10 \mu \mathrm{g}$ sufentanil is much greater than $20 \mu \mathrm{g}$ sufentanil since the combined sufentanil and bupivacaine fractional dose $\mathrm{ED}_{5}$ was found to be approximately one-third for sufentanil and one-tenth for bupivacaine (of the single-drug $\mathrm{ED}_{5} \mathrm{~d} \cdot{ }^{13}$

Although there have been several case reports of respiratory arrest associated with intrathecal sufentanil, ${ }^{14-16} 20 \mu \mathrm{g}$ ITS is felt to be safe for outpatient anesthesia. ${ }^{6}$ Factors which may increase the risk of respiratory arrest following intrathecal opioids include: high doses of opioid, repeated doses of opioid, intravenous sedatives or opioids, advanced age, co-existing disease, lack of opioid tolerance, and general anesthesia. ${ }^{9}$ Respiratory depression after ITS has been reported as early as four minutes after administration ${ }^{14}$ and as late as 30 min after administration. ${ }^{15} \mathrm{O}$ ur procedure duration ranged from 5 to $33 \mathrm{~min}$. Patients were then 
monitored in the recovery room for more than 30 min. The mean duration of anesthesia in outpatients who received $20 \mu \mathrm{g}$ ITS for extracorporeal shock wave lithotripsy was $64 \pm 13$ min, ${ }^{6}$ which clearly outlasted the time period at risk.

The abdominal toothed forceps skin test was not performed on the final study patient from Group LS, who had pressure discomfort with the vaginal speculum examination prior to laparoscopy and sharp perineal sensation on testing with a tenaculum. Her discomfort did not ease with $500 \mu \mathrm{g}$ alfentanil iv and, consequently, GA was induced. This was the first "failure" of a lidocaine-sufentanil spinal solution in three series of patients ${ }^{1-4}$ at our institution. Retrospectively, we should have performed the skin test of the abdomen, as per protocol. This patient may have been adequately blocked for the laparoscopic procedure, without sacral anesthesia, but we were so sensitized to the possibility of block failure that we prematurely converted to $\mathrm{GA}$.

Intrathecal $10 \mathrm{mg}$ lidocaine with $10 \mu \mathrm{g}$ sufentanil has been shown to be effective for laparoscopy, with the benefit of immediate postoperative ambulation, ${ }^{3}$ and reduced time to recovery of sensation to touch and pinprick compared to other low dose spinal anesthetic solutions. ${ }^{2}$ Intrathecal sufentanil is used effectively for labour and delivery analgesia with an $\mathrm{ED}_{50}$ and $\mathrm{ED}_{95}$ of 2.6 and $8.9 \mu \mathrm{g}$, respectively, in labouring women. ${ }^{17}$ In a study comparing $20 \mu \mathrm{g}$ ITS with conventional dose hyperbaric lidocaine for extracorporeal shock wave lithotripsy, there was no significant difference in supplementation required or in intraoperative and postoperative pain between groups. ${ }^{6}$ Patients receiving intrathecal sufentanil could ambulate, tolerate oral intake, and void earlier than the lidocaine group and were discharged home significantly earlier. ${ }^{6}$ The dose of $20 \mu \mathrm{g}$ ITS was felt by the authors to be a safe and effective dose that was not associated with excessive sedation. ${ }^{6}$ Intrathecal $20 \mu \mathrm{g}$ sufentanil has also been used successfully at our institution prior to this study for three short duration outpatient laparoscopic procedures.

In summary, $20 \mu \mathrm{g}$ sufentanil intrathecally is inferred by this study to be inferior to $10 \mathrm{mg}$ lidocaine with $10 \mu \mathrm{g}$ sufentanil intrathecally for providing adequate anesthesia reliably for short duration gynecological laparoscopic procedures. M oreover, there are no advantages with respect to side effects or rapidity of recovery of sensory and motor function.

Acknowledgments

The authors thank Dr Henry Woo, Department of Gynecology, Vancouver General H ospital, for his par- ticipation and encouragement. Assistance from the staff of the Surgical Day Care Centre is gratefully acknowledged.

\section{References}

1 Vaghadia H, M CLeod DH, Mitchell GWE, Merrick PM, Chilvers CR . Small-dose hypobaric lidocaine-fentanyl spinal anesthesia for short duration outpatient laparoscopy. I. A randomized comparison with conventional dose hyperbaric lidocaine. Anesth Analg 1997; 84: 59-64.

2 Chilvers CR, Vaghadia H, Mitchell GWE, Merrick PM. Small-dose hypobaric lidocaine-fentanyl spinal anesthesia for short duration oupatient laparoscopy. II. O ptimal fentanyl dose. Anesth Analg 1997; 84: 65-70.

3 Vaghadia H, Viskari D, Mitchell GWE, Berrill A. Selective spinal anesthesia for outpatient laparoscopy. I: Characteristics of three hypobaric solutions. $C$ an J Anesth 2001; 48: 256-60.

4 Vaghadia H, Solylo M A, H enderson C, M itchell GWE. Selective spinal anesthesia for outpatient laparoscopy. II: E pinephrine and spinal cord function. Can J Anesth 2001; 48: 261-66.

5 Cohen SE, Cherry CM, H ol brook R H J r, El-Sayed YY, Gibson R N , J affe R A . Intrathecal sufentanil for labor analgesia - sensory changes, side effects, and fetal heart rate changes. Anesth Analg 1993; 77: 1155-60.

6 Lau WC, Green CR, Faerber GJ, Tait AR, Golembi ewski JA . Intrathecal sufentanil for extracorporeal shock wave lithotripsy provides earlier discharge of the outpatient than intrathecal lidocaine. Anesth Analg 1997; 84: 1227-31.

7 Bromage PR. A comparison of the hydrochloride and carbon dioxide salts of lidocaine and prilocaine in epidural analgesia. Acta Anaesthesiol Scand 1965; 16(Suppl): 55-69.

8 Torda TA, PybusD A. Extradural administration of morphine and bupivicaine. A controlled comparison. Br J Anaesth 1984; 56: 141-6.

9 Chaney M A. Side effects of intrathecal and epidural opioids. Can J Anaesth 1995; 42: 891-903.

10 Jaffe R A, R owe M A. A comparison of the local anesthetic effects of meperidine, fentanyl and sufentanil on dorsal root axons. Anesth Analg 1996; 83: 776-81.

11 R iley ET, Walker D, $\mathrm{H}$ amilton $\mathrm{CL}$, Cohen SE. Intrathecal sufentanil for labor analgesia does not cause a sympathectomy. Anesthesiology 1997; 87: 874-8.

12 Riley ET, H amilton CL, C ohen SE. Intrathecal sufentanil produces sensory changes without hypotension in male volunteers. Anesthesiology 1998; 89: 73-8.

13 Camann W, A bouleish A, Eisenach J, H ood D, D atta S. Intrathecal sufentanil and epidural bupivicaine for labor analgesia: dose-response of individual agents and in 
combination. Reg Anesth Pain Med 1998; 23: 457-62.

14 Ferouz F, N orris M C, Leighton BL. Risk of respiratory arrest after intrathecal sufentanil. Anesth Analg 1997; 85: 1088-90.

15 Fournier R, Gamulin Z, Van Gessel E. Respiratory depression after $5 \mu \mathrm{g}$ of intrathecal sufentanil. Anesth Analg 1998; 87: 1377-8.

$16 \mathrm{~K}$ atsiris S, Williams S, Leighton $\mathrm{BL}, \mathrm{H}$ alpern $\mathrm{S}$. Respiratory arrest following intrathecal injection of sufentanil and bupivicaine in a parturient. $C$ an J Anaesth 1998; 45: 880-3.

17 H erman N L, Calicott R, Van Decar TK, Conlin G, Tilton J. Determination of the dose-response relationship for intrathecal sufentanil in laboring patients. Anesth Analg 1997; 84: 1256-61. 